OPEN ACCESS

Edited by:

Umberto Galderisi,

University of Campania Luigi Vanvitelli,

$$
\text { Italy }
$$

Reviewed by: Ying Cai,

Albert Einstein College of Medicine

United States

Jing-Woei $L i$,

Prince of Wales Hospital, China

*Correspondence:

Vesna D. Garovic

garovic.vesna@mayo.edu

${ }^{\dagger}$ These authors share first authorship

Specialty section:

This article was submitted to Preclinical Cell and Gene Therapy,

a section of the journal Frontiers in Bioengineering and Biotechnology

Received: 24 September 2021 Accepted: 09 December 2021 Published: 05 January 2022

Citation:

Ghamrawi R, Velickovic I, Milicevic O, White WM, Thistlethwaite $L R$,

Cunningham JM, Milosavljevic A, Milic NM and Garovic VD (2022) Buffy

Coat DNA Methylation Profile Is Representative of Methylation Patterns in White Blood Cell Types in Normal Pregnancy. Front. Bioeng. Biotechnol. 9:782843. doi: 10.3389/fbioe.2021.782843

\section{Buffy Coat DNA Methylation Profile Is Representative of Methylation Patterns in White Blood Cell Types in Normal Pregnancy}

\author{
Ranine Ghamrawi ${ }^{1+}$, Igor Velickovic ${ }^{2 \dagger}$, Ognjen Milicevic ${ }^{2}$, Wendy M. White ${ }^{3,4}$, \\ Lillian Rosa Thistlethwaite ${ }^{5}$, Julie M. Cunningham ${ }^{6}$, Aleksandar Milosavljevic ${ }^{5}$, \\ Natasa M. Milic ${ }^{1,2}$ and Vesna D. Garovic ${ }^{1,3 *}$
}

${ }^{1}$ Division of Nephrology and Hypertension, Department of Medicine, Mayo Clinic, Rochester, MN, United States, ${ }^{2}$ Department of Medical Statistics and Informatics, Medical Faculty University of Belgrade, Belgrade, Serbia, ${ }^{3}$ Department of Obstetrics and Gynecology, Mayo Clinic, Rochester, MN, United States, ${ }^{4}$ Department of Perinatology, Olmsted Medical Center, Rochester, MN, United States, ${ }^{5}$ Department of Molecular and Human Genetics, Baylor College of Medicine, Houston, TX. United States,

${ }^{6}$ Department of Laboratory Medicine and Pathology, Mayo Clinic, Rochester, MN, United States

Background: We aimed to assess the extent to which the buffy coat DNA methylome is representative of methylation patterns in constitutive white blood cell (WBC) types in normal pregnancy.

Methods: A comparison of differential methylation of buffy coat DNA vs DNA isolated from polymorphonuclear $(\mathrm{PMN})$ and lymphocytic fractions was performed for each blood sample obtained within $24 \mathrm{~h}$ prior to delivery from 29 normotensive pregnant women. Methylation profiles were obtained using an Illumina Human Methylation 450 BeadChip and CHaMP bioinformatics pipeline. A subset of differentially methylated probes (DMPs) showing discordant methylation were further investigated using statistical modeling and enrichment analysis.

Results: The smallest number of DMPs was found between the buffy coat and the PMN fraction (2.96\%). Pathway enrichment analysis of the DMPs identified biological pathways involved in the particular leukocyte lineage, consistent with perturbations during isolation. The comparisons between the buffy coat and the isolated fractions as a group using linear modeling yielded a small number of probes $(29,000)$ with discordant methylation. Demethylation of probes in the buffy coat compared to derived cell lines was more common and was prevalent in shelf and open sea regions.

Conclusion: Buffy coat is representative of methylation patterns in WBC types in normal pregnancy. The differential methylations are consistent with perturbations during isolation of constituent cells and likely originate in vitro due to the physical stress during cell separation and are of no physiological relevance. These findings help the interpretation of DNA methylation profiling in pregnancy and numerous other conditions.

Keywords: buffy coat, DNA methylation, epigenetics, white blood cells, pregnancy 


\section{INTRODUCTION}

DNA methylation, the addition of a 5-methyl group to a cytosine nucleotide at a cytosine-phosphate-guanine $(\mathrm{CpG})$ site, is an essential epigenetic modification implicated in switching on and off genes that control early mammalian embryogenesis, including development, differentiation, imprinting, and cellular function (Straussman et al., 2009; Portela and Esteller, 2010; Hodges et al., 2011; Jones, 2012). Many CpG sites are clustered in $\mathrm{CpG}$ islands which are flanked by shores and shelves (up to 2, and $2-4 \mathrm{~kb}$ from $\mathrm{CpG}$ islands, respectively) and are separated by "open sea" regions, which represent the rest of the genome. Tissue-specific DNA methylation tends to be observed within CpG shores rather than islands (Doi et al., 2009). DNA methylation frequently affects a gene promoter leading to gene silencing, while DNA methylation of the gene body indicates active transcription (Hellman and Chess, 2007).

Altered DNA methylation of regulatory regions has been shown to contribute to the control of proliferative, invasive, and immune tolerance mechanisms involved in oncogenesis (Klutstein et al., 2016; Kuss-Duerkop et al., 2018) - a disease process with many parallels to that of normal pregnancy-with the common goal of providing a nutrient supply and immune tolerance to a growing tumor and fetus, respectively. In our previous studies, we described a transient state of hypomethylation in maternal leukocyte DNA occurring in normal early pregnancy (White et al., 2012). We also have demonstrated that in preeclampsia-a pregnancy-specific hypertensive disorder clinically characterized by multisystem involvement and, commonly, proteinuria-maternal leukocyte DNA showed genome-wide differential methylation favoring hypermethylation compared with normotensive pregnant controls (White et al., 2013; White et al., 2016). Similar to other investigators, we have performed our studies on buffy coat, a mixed leukocyte cell population, which is obtained after centrifuging whole anticoagulated blood at low speeds (Houseman et al., 2015). The scientific rigor of such results critically depends on the ability to discern any experimentally introduced methylation changes.

The buffy coat of a healthy, non-pregnant individual contains white blood cells, leukocytes, which are comprised of $70 \%$ polymorphonuclear (PMN) leukocytes, also referred to as granulocytes $(0.5-1 \%$ basophils, $65 \%$ neutrophils and $2-4 \%$ eosinophils), and roughly $30 \%$ mononuclear cells (3-8\% monocytes, and 20-25\% lymphocytes). Consequently, buffy coat comparisons may be confounded by shifts in cell type composition, which occur both in physiological conditions and during disease processes. This may be of particular importance for pregnancy, when an increase in the number of PMN leukocytes and monocytes, together with a decrease in the number of lymphocytes, dendritic cells, and natural killer (NK) cells occurs (Naccasha et al., 2001; Luppi et al., 2002a; Luppi et al., 2002b). Preeclampsia has been shown to be associated with an increase in the number of neutrophils (Järemo et al., 2000), along with activation of other PMN leukocytes and monocytes (Sacks et al., 1999). These shifts in white blood cell composition that occur both in normotensive and preeclamptic pregnancies could affect the DNA methylation results found in the buffy coat (Adalsteinsson et al., 2012). As methylation can vary at specific loci among individual cell types, the shifts in buffy coat cell composition, rather than shifts in cellintrinsic methylation patterns, may cause methylation differences between buffy coat samples.

To date, limited work has addressed the stability and correlation of DNA methylation patterns in buffy coat compared with the different leukocyte fractions. Given our research focus on pregnancy and its complications, the objective of the current study was to assess to what extent the buffy coat methylome is representative of, or different from, the distinct cell types that it contains, namely PMN leukocytes and lymphocytes. To that end, we compared genome-wide methylation patterns in buffy coat to those of the PMN and lymphocytic fractions in the same pregnant individuals from blood samples collected within $24 \mathrm{~h}$ prior to delivery.

\section{MATERIALS AND METHODS}

\section{Sources for Cases and Blood Samples}

Pregnant women were recruited prospectively at Mayo Clinic in Rochester, MN, United States A convenience sample of $30 \mathrm{ml}$ of blood was drawn into an EDTA tube from normotensive pregnant women admitted for delivery and within the $24 \mathrm{~h}$ prior to giving birth. In each of 29 cases, the leukocytes were separated into three groups within 2 hours of collection. Using typical slow centrifugation, a buffy coat was made and immediately frozen. The remaining sample was further subdivided into a PMN and a lymphocytic fraction using a Ficoll gradient and subsequently frozen.

\section{Clinical Data}

The medical records were abstracted for data including age, ethnicity, gravidity, body mass index (BMI), and gestational age (GA) at the time of delivery.

\section{DNA Extraction and Processing}

In the buffy coat and PMN fraction, DNA was extracted using the AutoGenFlex DNA purification kit. In order to enrich the yield, manual extraction of DNA was performed for the lymphocytic fraction. Genomic DNA was quantified using a NanoDrop spectrophotometer, normalized with standard Pico Green methodology and plated. Bisulfite modification was performed using the EZ DNA Methylation Kit (Zymo Research).

\section{Methylation Assay}

Plate maps were generated to determine the random location for each sample on the plate, as well as the samples that were run in duplicate. All samples were run in a single batch. Bisulfite-treated DNA was hybridized and imaged on an Illumina Infinium Human Methylation $450 \mathrm{~K}$ BeadChip that can detect methylation levels at $486,685 \mathrm{CpG}$ dinucleotides across the genome and covers $96 \%$ of the $\mathrm{CpG}$ islands in the human genome. 


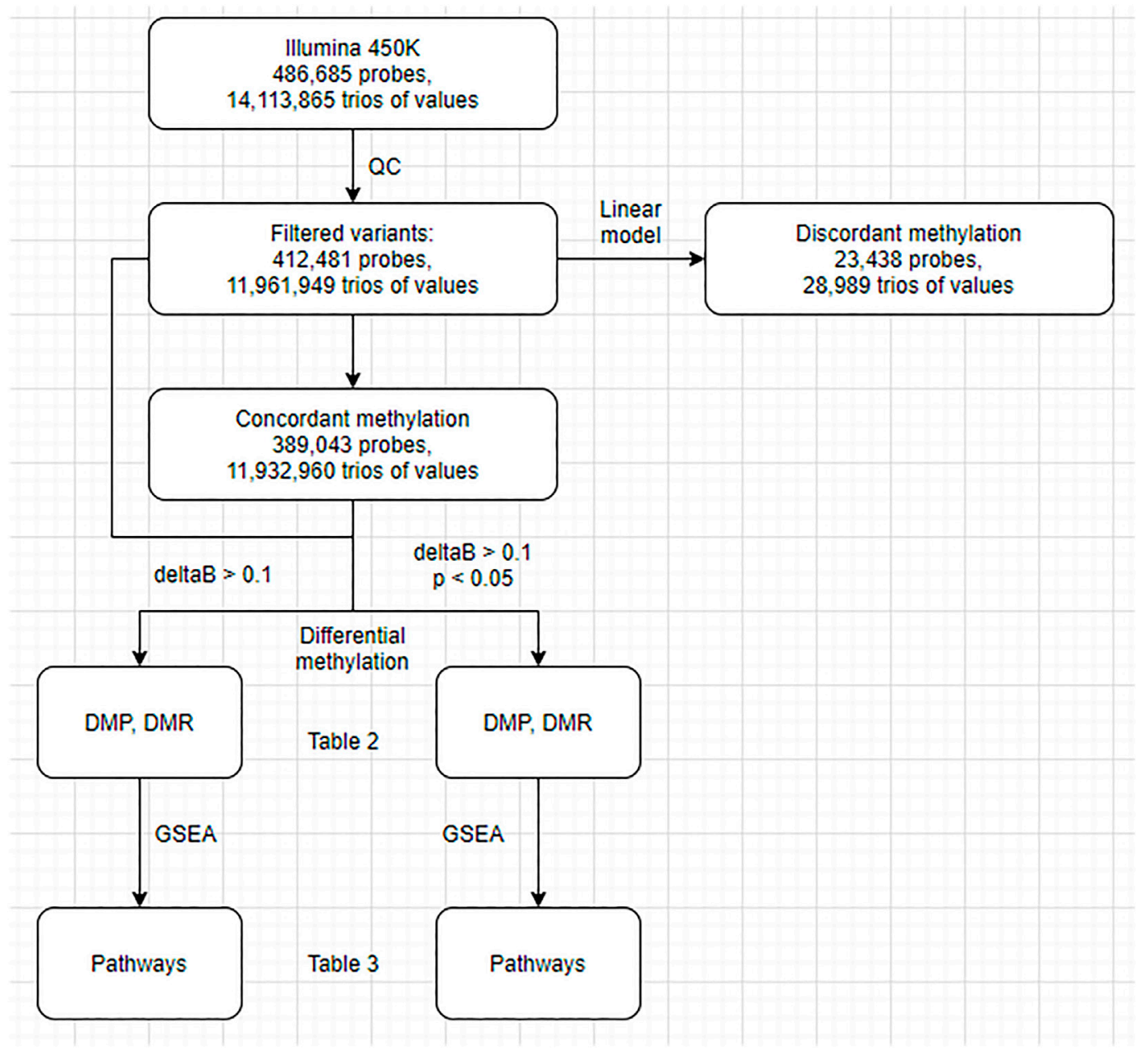

FIGURE 1 | Flowchart of the analysis. DMP, differentially methylated probes; DMR, differentially methylated regions; GSEA, gene set enrichment analysis.

\section{Quality Control}

The samples were processed and then scanned using Illumina's iScan instrumentation. The raw data were then analyzed using Illumina's Genome Studio software (version 2011.1), with methylation module (version 1.9.0). Quality assessment of the array was conducted using the "Control Dashboard" in the Genome Studio software package, which includes a graphical inspection of the 10 types of embedded control probes: staining, extension, hybridization, target removal, bisulfite conversion, G/T mismatch, specificity, non-polymorphic controls, negative controls, and restoration controls.

Overall sample performance was determined by the total number of detected CpGs, the average detection $p$ value across all $\mathrm{CpG}$ sites, and the distribution of average beta values for all CpGs. Call rates for each CpG site and sample were determined. Methylation sites and samples were excluded if the unreliable call rate (detection $p$-value) was greater than $5 \%$. Technical replicate reproducibility was estimated by the Pearson correlation coefficient.
While all samples were bisulfite modified and run concurrently to avoid batch effects, multiple BeadChips were used, and may have variations in assay integrity leading to the "chip" effect. Thus, data were examined using principal components analysis and subsequent unsupervised hierarchical clustering of obtained components.

\section{Statistical Analysis}

First, we conducted a standard differential methylation analysis to examine DNA methylation differences between the buffy coat and its PMN and lymphocytic fractions. Second, we aimed to differentiate between true differential methylation and discordant methylation, the latter being defined as methylation of specific CPGs in the buffy coat that did not match their methylation status in derived (PMN and lymphocytic) fractions (Figure 1). We used linear modeling to determine whether the linear combination of methylation profiles from PMN and lymphocytic fractions predicts the methylation profile of the buffy coat. Assuming that the methylation status of each $\mathrm{CPG}$ 


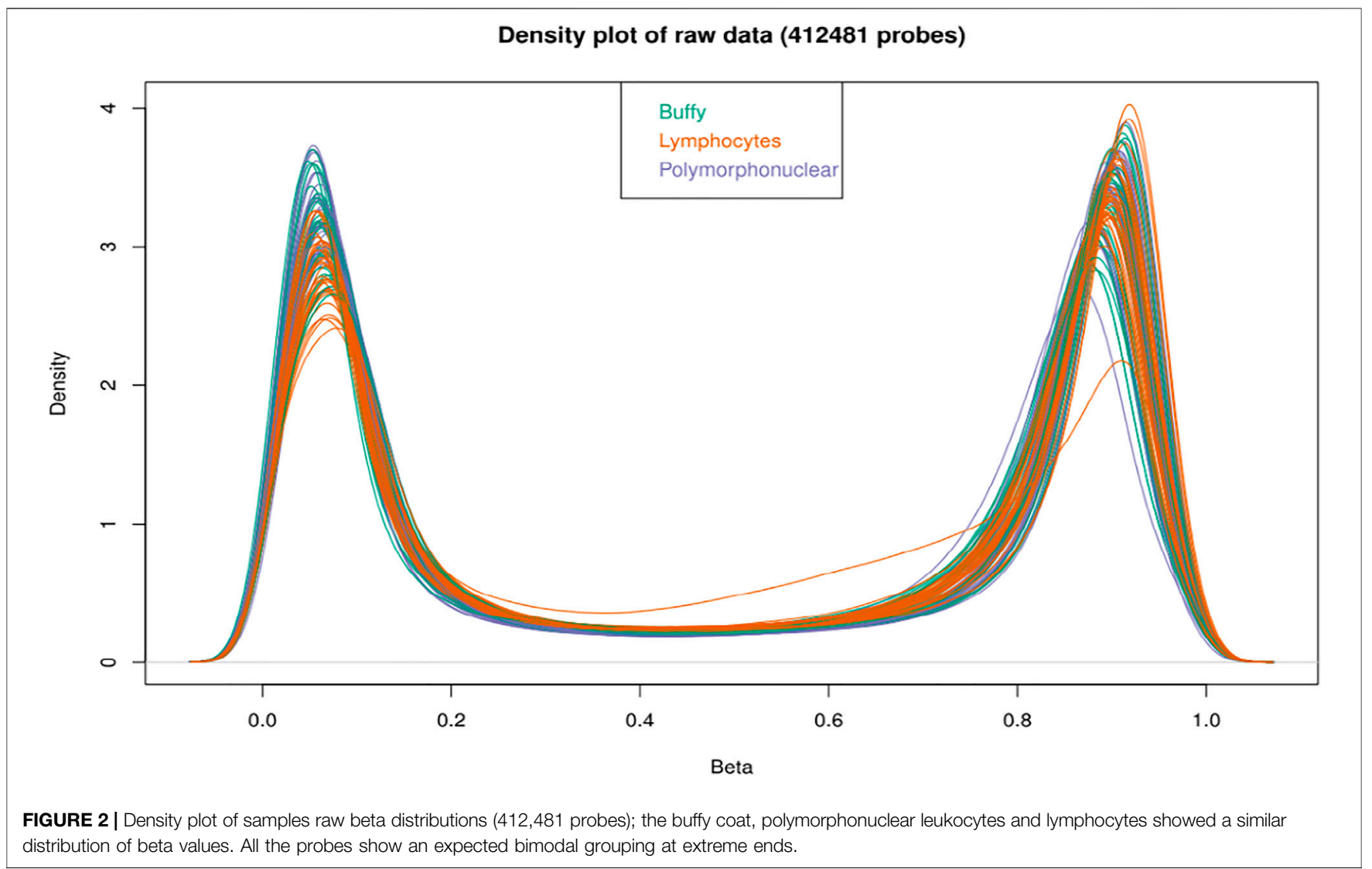

site in the buffy coat will agree with the methylation status in the derived fractions, we identified concordant (the presence of prediction/agreement) and discordant (the lack of prediction/ agreement) CpGs. Third, we attempted to investigate the factors predicting discordance (e.g., presence of nearby SNPs, GC composition of probes, presence of motifs).

Analysis of the differential methylation at the individual $\mathrm{CpG}$ probe level (DMP) was performed using the Limma package (version 3.30.13) (Smyth, 2004). To adjust for multiple comparisons, we used the Benjamini-Hochberg procedure of multiple testing, with $\alpha=0.05$. Analysis of the differentially methylated regions (DMR) as aggregates of individual probes was performed using the DMRcate package (Peters et al., 2015). In DMRcate, a default false discovery rate (FDR) cutoff of 0.05 was used for CpG sites. The data generated by DMR and DMP were used as an input for Figure 2. Gene set enrichment analysis (GSEA) was performed using the Gometh method to avoid probes-per-gene bias (Young et al., 2010; Geeleher et al., 2013; Phipson et al., 2016). Another filtering criterion, in addition to statistical significance, was differences in beta (delta beta) larger than 0.1. For the purposes of enrichment and correlation analyses, we used the GRCh37 reference build. The mappability and uniqueness of probes was calculated using Bismap (Karimzadeh et al., 2018). Normalized beta values and sample annotations are available to the public at https://osf.io/ 324ak/?view_only $=$ 5c1c7cf5b77a40d3bb29b7d9c418f763.
TABLE 1 | Study population demographics.

Demographics

All patients $(n=29)$

Age, yrs (mean $\pm \mathrm{SD})$

White, $n(\%)$

Gravida, $n(\%)$

$>1$

Parity, $n(\%)$

0

1

$>1$

BMl, $\left(\mathrm{kg} / \mathrm{m}^{2}\right)$, (mean $\left.\pm \mathrm{SD}\right)$

$\mathrm{GA}$ at delivery, weeks, (mean $\pm \mathrm{SD}$ )

$29.2 \pm 6.0$

24 (82.8)

$13(44.8)$

$16(55.2)$

14 (48.3)

4 (13.8)

$11(37.9)$

$29.3 \pm 7.7$

$39.9 \pm 1.4$

$B M I$, body mass index; $G A$, gestational age; $S D$, standard deviation.

\section{RESULTS}

\section{Clinical Characteristics}

The blood samples of 29 normotensive pregnancies were collected and analyzed. Patients were predominantly white, and the mean gestational age at delivery was $39.9 \pm 1.4$ weeks. Demographic and clinical characteristics are listed in Table 1.

\section{Differential Methylation}

A total of 412,481 probes passed all the filters (Figure 3). A pairwise comparison between the buffy coat, PMN leukocytes, 
All samples before normalization (412481 probes)

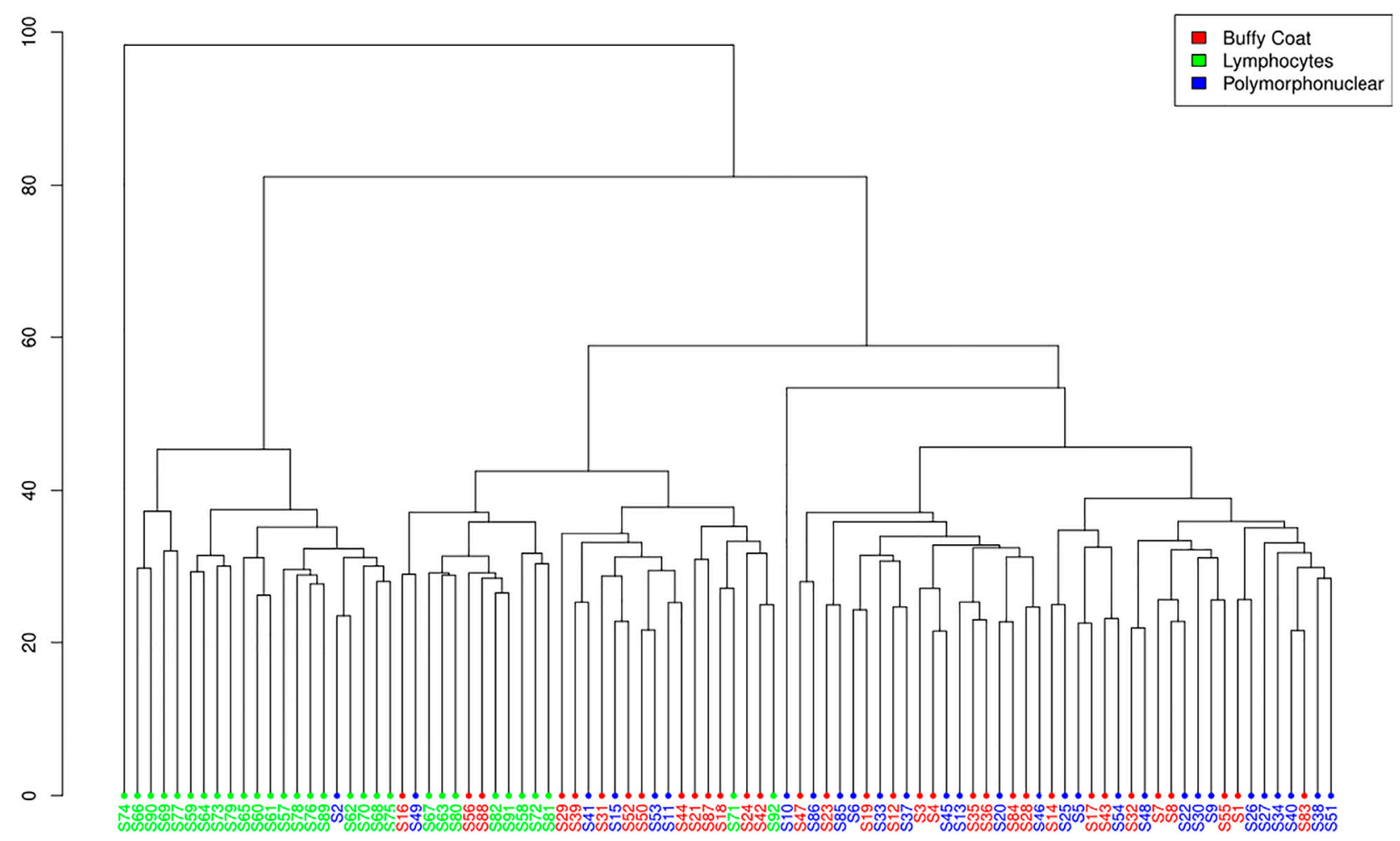

FIGURE 3 | Hierarchal clustering of all samples before normalization (412,481 probes) on Illumina 450K data.

TABLE 2 | Number of differentially methylated probes and regions.

\begin{tabular}{|c|c|c|c|c|c|c|c|}
\hline \multirow{2}{*}{$\begin{array}{l}\text { Differentially } \\
\text { methylated }\end{array}$} & \multirow[t]{2}{*}{ Significance filters } & \multicolumn{3}{|c|}{ Original analysis } & \multicolumn{3}{|c|}{ Without violating probe trios ${ }^{a}$} \\
\hline & & BP & BL & PL & BP & BL & PL \\
\hline \multirow[t]{2}{*}{ DMP } & $p<0.05$ & 12,207 & 125,962 & 143,097 & 13,926 & 124,251 & 143,048 \\
\hline & $p<0.05$ and $\Delta \beta>0.1$ & 2,450 & 20,271 & 26,334 & 2,963 & 20,303 & 26,495 \\
\hline \multirow[t]{2}{*}{ DMR } & $p<0.05$ & 596 & 5,270 & 6,086 & 627 & 5,209 & 6,120 \\
\hline & $p<0.05$ and $\Delta \beta>0.1$ & 0 & 164 & 25 & 0 & 157 & 24 \\
\hline \multirow[t]{2}{*}{ GSEA-DMP } & $p<0.05$ & 15 & 0 & 0 & 14 & 0 & 0 \\
\hline & $p<0.05$ and $\Delta \beta>0.1$ & 11 & 32 & 17 & 12 & 31 & 23 \\
\hline \multirow[t]{2}{*}{ GSEA-DMR } & $p<0.05$ & 0 & 10 & 19 & 0 & 14 & 23 \\
\hline & $p<0.05$ and $\Delta \beta>0.1$ & 0 & 1 & 1 & 0 & 0 & 0 \\
\hline
\end{tabular}

${ }^{a}$ Analysis of differentially methylated probes after elimination of outliers.

$D M P$, differentially methylated probes; DMR, differentially methylated regions; GSEA, gene set enrichment analysis.

$B P$, Comparison of buffy coat to polymorphonuclear leukocytes; BL, comparison of buffy coat to lymphocytes; PL, comparison of polymorphonuclear leukocytes to lymphocytes.

and lymphocytes was performed to identify differentially methylated probes (DMP). When considering the $\alpha=0.05$ significance level with Benjamini-Hochberg multiple testing corrections, the greatest number of differentially methylated sites was found between PMN and lymphocytes (143,097; $34.69 \%)$, and the smallest between the buffy coat and PMN $(12,207 ; 2.96 \%)$, as represented in Table 2 . This finding is not unexpected, considering that the buffy coat contains predominantly PMN leukocytes, so in this case only a small proportion of other cells (mainly lymphocytes) was present and contributed to differential signals. The opposite rationale can be drawn for the comparison of buffy coat and lymphocyte fractions. Clustering in Figure 3 corroborates this with a clearly distinct lymphocyte fraction and an overlap of the other two fractions. The analysis was subsequently repeated for differentially methylated regions (DMR), but these results have moderate interpretability due to the variable sizes of a region, and they primarily served as an input for gene set enrichment analysis 


\section{A}

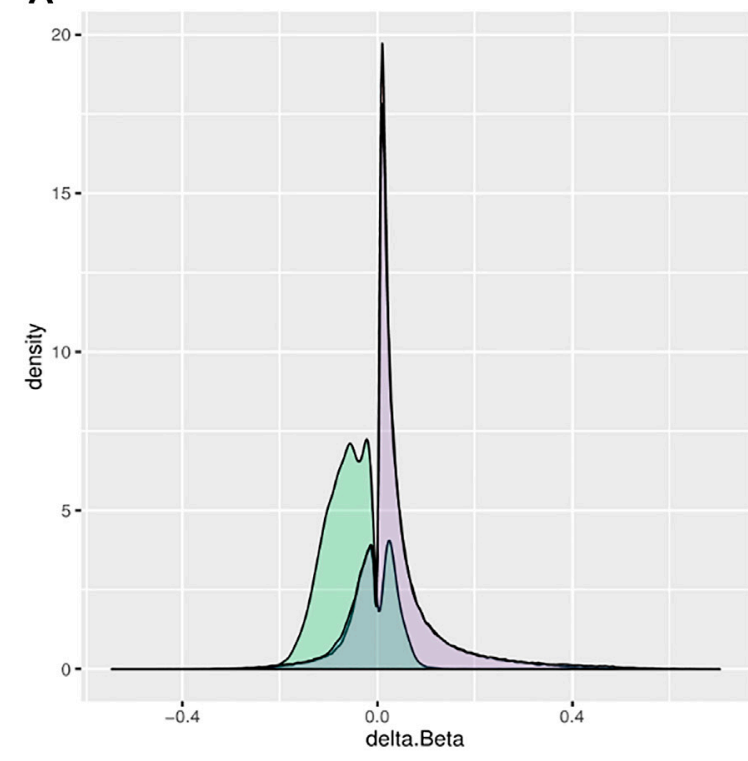

B

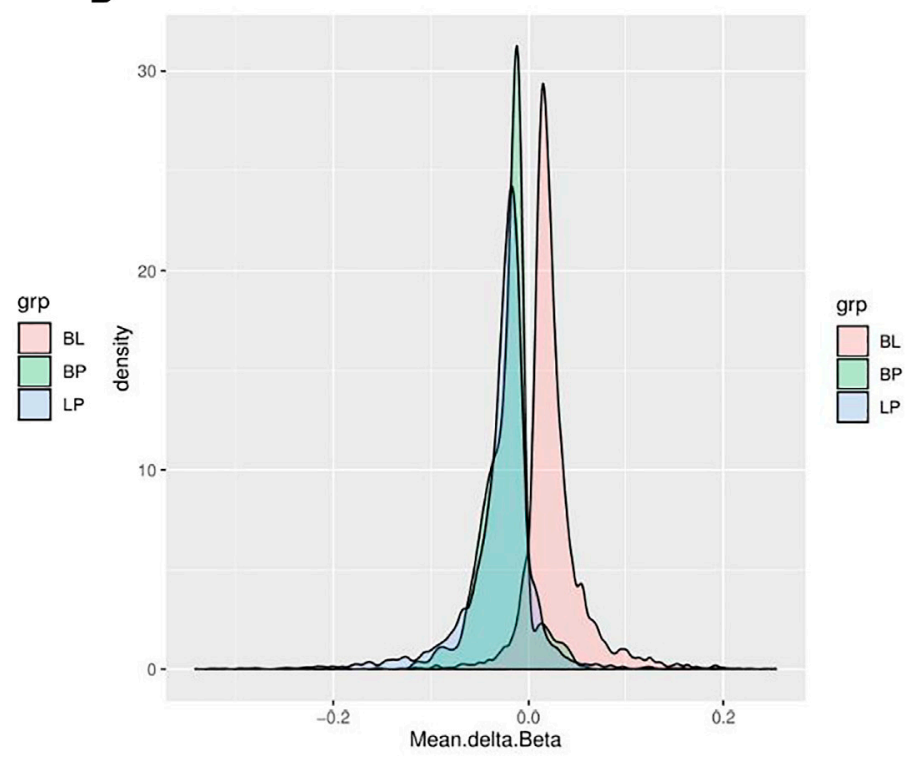

FIGURE 4 | Probability density functions for the effect size between groups. These distributions are useful for selecting cutoffs for differential methylation. (A) Differences in beta values for differentially methylated probes. (B) Differences in mean delta beta for differentially methylated regions. BP, Comparison of buffy coat to polymorphonuclear leukocytes: BL, Comparison of buffy coat to lymphocytes; PL, Comparison of polymorphonuclear leukocytes to lymphocytes.

(GSEA). The magnitudes of differences for both the DMP and DMR analyses are shown in Figure 4A (delta beta) and 4 B (mean beta fold change). In addition, the number of differentially methylated probes/regions between the groups are shown when the applied threshold for delta beta was 0.1 (Original Analysis in Table 2).

\section{Gene Set Enrichment Analysis}

Gene set enrichment analysis (GSEA) was performed using either only $p<0.05$, or by combining $p<0.05$ with delta beta $>0.1$. When using only $p$-values, DMPs give enriched gene sets only for the buffy coat to polymorphonuclear leukocytes (BP) pairing, where the least differences in methylation are expected. Matching DMR analyses give opposite (and expected) results with no gene sets for the BP and a larger number of sets in the polymorphonuclear leukocytes to lymphocyte (PL) pairing. The pathways identified tended to be general in nature, e.g., gene silencing by miRNA, mRNA binding involved in posttranscriptional gene silencing, and micro-ribonucleoprotein complex (Table 2). In contrast, when we used delta beta values as an additional filter, GSEA generated several pathways for DMP and virtually no pathways for DMR, and the resulting pathways were indicative of the leukocyte lineages, e.g., innate immune response, inflammatory response, and neutrophil degranulation (Table 3).

\section{Consistency of Results Between Leukocyte Fractions and the Buffy Coat}

Under the assumption that the buffy coat is mostly the weighted sum of PMN and lymphocytes, buffy coat methylations are essentially estimated twice. We took advantage of the redundant methylation information to test whether we could extract the ratio of PMN and lymphocytes in the peripheral blood. Without additional constraints, we fit the model buffy coat $\sim$ lymphocytes + PMN leukocytes + error for each subject and obtained coefficients for both lymphocytes and PMN summing to 0.98-0.99. This shows that the model is valid and reflects the physiological setup. The coefficients were interpreted as the differential blood count, with an expectancy of $20-40 \%$ lymphocytes and 40-80\% PMN leukocytes.

We next performed linear modeling to determine whether the weighted combination of methylation profiles from isolated cellular fractions predicts the methylation profile of the buffy coat and identified the discordant CpG probes where the weighted combination deviates from methylation measured on the buffy coat. We applied the fitted model to each probe and each trio of samples and calculated the residuals (Figure 5). Although most probes centered around zero in a unimodal distribution, there was a prominent peak around the negative extreme (Figure 6), which corresponds to CpGs that are less methylated in the buffy coat than predicted from the relatively high $\mathrm{CpG}$ methylation in constituent fractions. Positive residuals correspond to methylated loci in buffy coat for which either of the fractions is hypomethylated and we can see several clusters between 0.3 and 0.8 . Notably, the negative peak at the far left is dominant and has no matching positive counterpart. These discordant values with absolute residuals larger than expected could be a consequence of random probe errors or may be a result of physical/chemical stress occurring during cell separation, thus leading to methylation in isolated cellular fractions of 
TABLE 3 | Gene sets obtained.

\begin{tabular}{|c|c|c|c|c|c|c|c|}
\hline \multirow[t]{2}{*}{ Method } & \multirow{2}{*}{$\begin{array}{l}\text { Sig. } \\
\text { Filters }\end{array}$} & \multicolumn{3}{|c|}{ Original analysis } & \multicolumn{3}{|c|}{ Without violating probe trios* } \\
\hline & & BP & BL & PL & BP & BL & PL \\
\hline \multirow[t]{42}{*}{$\begin{array}{l}\text { GSEA- } \\
\text { DMP }\end{array}$} & $\begin{array}{l}p< \\
0.05\end{array}$ & $\begin{array}{l}\text { 1.neutrophil } \\
\text { degranulation }\end{array}$ & & & & & \\
\hline & & 2.specific granule & & & 1.neutrophil & & \\
\hline & & membrane & & & degranulation & & \\
\hline & & 3.specific granule & & & 2.specific granule & & \\
\hline & & lumen & & & membrane & & \\
\hline & & 4.signal & & & 3.tertiary granule & & \\
\hline & & transduction & & & membrane & & \\
\hline & & $\begin{array}{l}\text { 5.tertiary granule } \\
\text { membrane }\end{array}$ & & & $\begin{array}{l}\text { 4.external side of } \\
\text { plasma membrane }\end{array}$ & & \\
\hline & & $\begin{array}{l}\text { 6.external side of } \\
\text { plasma membrane }\end{array}$ & & & 5.actin binding & & \\
\hline & & $\begin{array}{l}\text { 7.inflammatory } \\
\text { response }\end{array}$ & & & 6.immune response & & \\
\hline & & 8.cellular response & & & 7.signal transduction & & \\
\hline & & to & & & & & \\
\hline & & lipopolysaccharide & & & & & \\
\hline & & 9.humoral immune & & & 8.specific granule & & \\
\hline & & response & & & lumen & & \\
\hline & & 10.innate immune & & & 9.innate immune & & \\
\hline & & response & & & response & & \\
\hline & & 11.positive & & & 10.positive regulation & & \\
\hline & & regulation of & & & of interleukin-10 & & \\
\hline & & interleukin-10 & & & production & & \\
\hline & & production & & & & & \\
\hline & & 12.actin binding & & & $\begin{array}{l}\text { 11.humoral immune } \\
\text { response }\end{array}$ & & \\
\hline & & 13.plasma & & & 12.tertiary granule & & \\
\hline & & membrane & & & lumen & & \\
\hline & & 14.antimicrobial & & & 13.positive regulation & & \\
\hline & & humoral response & & & of I-kappaB kinase/ & & \\
\hline & & & & & NF-kappaB signaling & & \\
\hline & & $\begin{array}{l}\text { 15.tertiary granule } \\
\text { lumen }\end{array}$ & & & $\begin{array}{l}\text { 14.cellular response to } \\
\text { lipopolysaccharide }\end{array}$ & & \\
\hline & $p<$ & 1.neutrophil & 1.neutrophil & 1.neutrophil & 1.neutrophil & 1.neutrophil & 1.neutrophil \\
\hline & 0.05 & degranulation & degranulation & degranulation & degranulation & degranulation & degranulation \\
\hline & \& & 2.specific granule & 2.inflammatory & 2.inflammatory & 2.specific granule & 2.inflammatory & 2.inflammatory \\
\hline & $\Delta \beta>0.1$ & lumen & response & response & lumen & response & response \\
\hline & & $\begin{array}{l}\text { 3.specific granule } \\
\text { membrane }\end{array}$ & $\begin{array}{l}\text { 3.specific granule } \\
\text { membrane }\end{array}$ & $\begin{array}{l}\text { 3.specific granule } \\
\text { membrane }\end{array}$ & $\begin{array}{l}\text { 3.specific granule } \\
\text { membrane }\end{array}$ & $\begin{array}{l}\text { 3.specific granule } \\
\text { membrane }\end{array}$ & $\begin{array}{l}\text { 3.innate immune } \\
\text { response }\end{array}$ \\
\hline & & $\begin{array}{l}\text { 4.antimicrobial } \\
\text { humoral response }\end{array}$ & $\begin{array}{l}\text { 4.innate immune } \\
\text { response }\end{array}$ & $\begin{array}{l}\text { 4.innate immune } \\
\text { response }\end{array}$ & 4.cytosol & $\begin{array}{l}\text { 4.innate immune } \\
\text { response }\end{array}$ & $\begin{array}{l}\text { 4.specific granule } \\
\text { membrane }\end{array}$ \\
\hline & & $\begin{array}{l}\text { 5.innate immune } \\
\text { response }\end{array}$ & $\begin{array}{l}\text { 5.cytokine-mediated } \\
\text { signaling pathway }\end{array}$ & 5.signal transduction & $\begin{array}{l}\text { 5.antimicrobial } \\
\text { humoral response }\end{array}$ & $\begin{array}{l}\text { 5.cytokine-mediated } \\
\text { signaling pathway }\end{array}$ & 5.signal transduction \\
\hline & & $\begin{array}{l}\text { 6.tertiary granule } \\
\text { lumen }\end{array}$ & 6.immune response & $\begin{array}{l}\text { 6.cytokine-mediated } \\
\text { signaling pathway }\end{array}$ & $\begin{array}{l}\text { 6.tertiary granule } \\
\text { lumen }\end{array}$ & 6.signal transduction & $\begin{array}{l}\text { 6.cytokine-mediated } \\
\text { signaling pathway }\end{array}$ \\
\hline & & 7.cytosol & 7.signal transduction & 7.immune response & $\begin{array}{l}\text { 7.innate immune } \\
\text { response }\end{array}$ & 7.immune response & 7.immune response \\
\hline & & $\begin{array}{l}\text { 8.tertiary granule } \\
\text { membrane }\end{array}$ & $\begin{array}{l}\text { 8.specific granule } \\
\text { lumen }\end{array}$ & $\begin{array}{l}\text { 8.lipopolysaccharide- } \\
\text { mediated signaling } \\
\text { pathway }\end{array}$ & $\begin{array}{l}\text { 8. defense response to } \\
\text { bacterium }\end{array}$ & $\begin{array}{l}\text { 8.specific granule } \\
\text { lumen }\end{array}$ & $\begin{array}{l}\text { 8.lipopolysaccharide- } \\
\text { mediated signaling } \\
\text { pathway }\end{array}$ \\
\hline & & $\begin{array}{l}\text { 9.defense } \\
\text { response to } \\
\text { bacterium }\end{array}$ & $\begin{array}{l}\text { 9.tertiary granule } \\
\text { membrane }\end{array}$ & $\begin{array}{l}\text { 9.tertiary granule } \\
\text { membrane }\end{array}$ & 9.protein binding & $\begin{array}{l}\text { 9.lipopolysaccharide- } \\
\text { mediated signaling } \\
\text { pathway }\end{array}$ & $\begin{array}{l}\text { 9.tertiary granule } \\
\text { membrane }\end{array}$ \\
\hline & & $\begin{array}{l}\text { 10.azurophil } \\
\text { granule lumen }\end{array}$ & $\begin{array}{l}\text { 10.lipopolysaccharide- } \\
\text { mediated signaling } \\
\text { pathway }\end{array}$ & $\begin{array}{l}\text { 10.external side of } \\
\text { plasma membrane }\end{array}$ & $\begin{array}{l}\text { 10.azurophil granule } \\
\text { lumen }\end{array}$ & $\begin{array}{l}\text { 10.tertiary granule } \\
\text { membrane }\end{array}$ & $\begin{array}{l}\text { 10.cellular response to } \\
\text { lipopolysaccharide }\end{array}$ \\
\hline & & 11.protein binding & $\begin{array}{l}\text { 11.positive regulation of } \\
\text { GTPase activity }\end{array}$ & 11.chemotaxis & $\begin{array}{l}\text { 11.tertiary granule } \\
\text { membrane }\end{array}$ & $\begin{array}{l}\text { 11.positive regulation } \\
\text { of GTPase activity }\end{array}$ & $\begin{array}{l}\text { 11.external side of } \\
\text { plasma membrane }\end{array}$ \\
\hline & & & $\begin{array}{l}\text { 12.B cell receptor } \\
\text { signaling pathway }\end{array}$ & $\begin{array}{l}\text { 12.signaling receptor } \\
\text { activity }\end{array}$ & $\begin{array}{l}\text { 12.endoribonuclease } \\
\text { activity }\end{array}$ & $\begin{array}{l}\text { 12.positive regulation } \\
\text { of I-kappaB kinase/ } \\
\text { NF-kappaB signaling }\end{array}$ & $\begin{array}{l}\text { 12.positive regulation } \\
\text { of I-kappaB kinase/ } \\
\text { NF-kappaB signaling }\end{array}$ \\
\hline
\end{tabular}


TABLE 3 | (Continued) Gene sets obtained.

\begin{tabular}{|c|c|c|c|c|c|c|c|}
\hline \multirow[t]{2}{*}{ Method } & \multirow{2}{*}{$\begin{array}{l}\text { Sig. } \\
\text { Filters }\end{array}$} & \multicolumn{3}{|c|}{ Original analysis } & \multicolumn{3}{|c|}{ Without violating probe trios* } \\
\hline & & BP & BL & PL & BP & BL & PL \\
\hline & & & $\begin{array}{l}\text { 13.cellular response to } \\
\text { lipopolysaccharide }\end{array}$ & $\begin{array}{l}\text { 13.cellular response to } \\
\text { lipopolysaccharide }\end{array}$ & & $\begin{array}{l}\text { 13.cellular response to } \\
\text { lipopolysaccharide }\end{array}$ & $\begin{array}{l}\text { 13.B cell receptor } \\
\text { signaling pathway }\end{array}$ \\
\hline & & & $\begin{array}{l}\text { 14.positive regulation of } \\
\text { I-kappaB kinase/NF- } \\
\text { kappaB signaling }\end{array}$ & $\begin{array}{l}\text { 14.positive regulation } \\
\text { of GTPase activity }\end{array}$ & & $\begin{array}{l}\text { 14.B cell receptor } \\
\text { signaling pathway }\end{array}$ & $\begin{array}{l}\text { 14.positive regulation } \\
\text { of interleukin-2 } \\
\text { biosynthetic process }\end{array}$ \\
\hline & & & $\begin{array}{l}\text { 15.secretory granule } \\
\text { membrane }\end{array}$ & $\begin{array}{l}\text { 15.positive regulation } \\
\text { of I-kappaB kinase/ } \\
\text { NF-kappaB signaling }\end{array}$ & & $\begin{array}{l}\text { 15.secretory granule } \\
\text { membrane }\end{array}$ & 15.cell surface \\
\hline & & & 16.cell surface & $\begin{array}{l}\text { 16.secretory granule } \\
\text { membrane }\end{array}$ & & 16.T cell activation & $\begin{array}{l}\text { 16.signaling receptor } \\
\text { activity }\end{array}$ \\
\hline & & & 17.T cell activation & 17.T cell activation & & 17.chemotaxis & 17.chemotaxis \\
\hline & & & $\begin{array}{l}\text { 18. perinuclear region of } \\
\text { cytoplasm }\end{array}$ & & & 18.cell surface & $\begin{array}{l}\text { 18.secretory granule } \\
\text { membrane }\end{array}$ \\
\hline & & & 19.chemotaxis & & & $\begin{array}{l}\text { 19.negative regulation } \\
\text { of tumor necrosis } \\
\text { factor production }\end{array}$ & 19.cell-cell adhesion \\
\hline & & & 20.Golgi apparatus & & & $\begin{array}{l}\text { 20.tertiary granule } \\
\text { lumen }\end{array}$ & 20.T cell activation \\
\hline & & & $\begin{array}{l}21 \text {.negative regulation } \\
\text { of tumor necrosis factor } \\
\text { production }\end{array}$ & & & $\begin{array}{l}\text { 21.cellular defense } \\
\text { response }\end{array}$ & $\begin{array}{l}\text { 21.positive regulation } \\
\text { of GTPase activity }\end{array}$ \\
\hline & & & $\begin{array}{l}\text { 22.tertiary granule } \\
\text { lumen }\end{array}$ & & & 22.T cell costimulation & 22.focal adhesion \\
\hline & & & $\begin{array}{l}\text { 23.cellular defense } \\
\text { response }\end{array}$ & & & $\begin{array}{l}\text { 23.adaptive immune } \\
\text { response }\end{array}$ & $\begin{array}{l}\text { 23. negative regulation } \\
\text { of tumor necrosis } \\
\text { factor production }\end{array}$ \\
\hline & & & 24. $T$ cell costimulation & & & 24.cytosol & \\
\hline & & & 25.adaptive immune & & & 25.platelet activation & \\
\hline & & & response & & & & \\
\hline & & & 26.platelet activation & & & $\begin{array}{l}\text { 26.GTPase activator } \\
\text { activity }\end{array}$ & \\
\hline & & & $\begin{array}{l}\text { 27.regulation of } \\
\text { immune response }\end{array}$ & & & 27.Golgi apparatus & \\
\hline & & & $\begin{array}{l}\text { 28.GTPase activator } \\
\text { activity } \\
\text { 29.cytosol }\end{array}$ & & & $\begin{array}{l}\text { 28.regulation of } \\
\text { immune response } \\
\text { 29.perinuclear region } \\
\text { of cytoplasm }\end{array}$ & \\
\hline & & & 30.external side of & & & 30.extracellular & \\
\hline & & & plasma membrane & & & exosome & \\
\hline & & & 31.Golgi membrane & & & 31.Golgi membrane & \\
\hline & & & 32.extracellular & & & & \\
\hline & & & exosome & & & & \\
\hline \multirow[t]{6}{*}{$\begin{array}{l}\text { GSEA- } \\
\text { DMR }\end{array}$} & $\begin{array}{l}p< \\
0.05\end{array}$ & & $\begin{array}{l}\text { 1.mRNA binding } \\
\text { involved in } \\
\text { posttranscriptional } \\
\text { gene silencing }\end{array}$ & $\begin{array}{l}\text { 1.gene silencing by } \\
\text { miRNA }\end{array}$ & & $\begin{array}{l}\text { 1.mRNA binding } \\
\text { involved in } \\
\text { posttranscriptional } \\
\text { gene silencing }\end{array}$ & $\begin{array}{l}\text { 1.gene silencing by } \\
\text { miRNA }\end{array}$ \\
\hline & & & $\begin{array}{l}\text { 2.micro- } \\
\text { ribonucleoprotein } \\
\text { complex }\end{array}$ & $\begin{array}{l}\text { 2.mRNA binding } \\
\text { involved in } \\
\text { posttranscriptional } \\
\text { gene silencing }\end{array}$ & & $\begin{array}{l}\text { 2.micro- } \\
\text { ribonucleoprotein } \\
\text { complex }\end{array}$ & $\begin{array}{l}\text { 2.mRNA binding } \\
\text { involved in } \\
\text { posttranscriptional } \\
\text { gene silencing }\end{array}$ \\
\hline & & & $\begin{array}{l}\text { 3.gene silencing by } \\
\text { miRNA }\end{array}$ & $\begin{array}{l}\text { 3.micro- } \\
\text { ribonucleoprotein } \\
\text { complex }\end{array}$ & & $\begin{array}{l}\text { 3.gene silencing by } \\
\text { miRNA }\end{array}$ & $\begin{array}{l}\text { 3.micro- } \\
\text { ribonucleoprotein } \\
\text { complex }\end{array}$ \\
\hline & & & 4.extracellular space & 4.extracellular space & & 4.extracellular space & 4.extracellular space \\
\hline & & & $\begin{array}{l}\text { 5.DNA-binding } \\
\text { transcription activator } \\
\text { activity, RNA } \\
\text { polymerase II-specific }\end{array}$ & $\begin{array}{l}\text { 5.DNA-binding } \\
\text { transcription activator } \\
\text { activity, RNA } \\
\text { polymerase II-specific }\end{array}$ & & $\begin{array}{l}\text { 5.DNA-binding } \\
\text { transcription activator } \\
\text { activity, RNA } \\
\text { polymerase II-specific }\end{array}$ & 5.extracellular region \\
\hline & & & 6.uterus development & 6.extracellular region & & 6.extracellular region & $\begin{array}{l}\text { 6.DNA-binding } \\
\text { transcription activator } \\
\text { activity, RNA } \\
\text { polymerase II-specific } \\
\text { ed on following page) }\end{array}$ \\
\hline
\end{tabular}


TABLE 3 | (Continued) Gene sets obtained.

\begin{tabular}{|c|c|c|c|c|c|c|c|}
\hline \multirow[t]{2}{*}{ Method } & \multirow{2}{*}{$\begin{array}{l}\text { Sig. } \\
\text { Filters }\end{array}$} & \multicolumn{3}{|c|}{ Original analysis } & \multicolumn{3}{|c|}{ Without violating probe trios* } \\
\hline & & BP & BL & PL & BP & BL & PL \\
\hline & & & $\begin{array}{l}\text { 7.DNA-binding } \\
\text { transcription factor } \\
\text { activity, RNA } \\
\text { polymerase II-specific }\end{array}$ & $\begin{array}{l}\text { 7.integral component } \\
\text { of plasma membrane }\end{array}$ & & 7.uterus development & $\begin{array}{l}\text { 7.integral component } \\
\text { of plasma membrane }\end{array}$ \\
\hline & & & 8.extracellular region & $\begin{array}{l}\text { 8.collagen-containing } \\
\text { extracellular matrix }\end{array}$ & & $\begin{array}{l}\text { 8.embryonic forelimb } \\
\text { morphogenesis }\end{array}$ & $\begin{array}{l}\text { 8.collagen-containing } \\
\text { extracellular matrix }\end{array}$ \\
\hline & & & 9.odontogenesis & $\begin{array}{l}\text { 9.DNA-binding } \\
\text { transcription factor } \\
\text { activity, RNA } \\
\text { polymerase II-specific }\end{array}$ & & 9.odontogenesis & $\begin{array}{l}\text { 9.sequence-specific } \\
\text { DNA binding }\end{array}$ \\
\hline & & & $\begin{array}{l}\text { 10.embryonic forelimb } \\
\text { morphogenesis }\end{array}$ & $\begin{array}{l}\text { 10.embryonic forelimb } \\
\text { morphogenesis }\end{array}$ & & $\begin{array}{l}\text { 10.positive regulation } \\
\text { of neuron } \\
\text { differentiation }\end{array}$ & $\begin{array}{l}\text { 10.DNA-binding } \\
\text { transcription factor } \\
\text { activity, RNA } \\
\text { polymerase II-specific }\end{array}$ \\
\hline & & & & $\begin{array}{l}\text { 11.dopaminergic } \\
\text { neuron differentiation }\end{array}$ & & $\begin{array}{l}\text { 11.collagen- } \\
\text { containing } \\
\text { extracellular matrix }\end{array}$ & $\begin{array}{l}\text { 11.embryonic forelimb } \\
\text { morphogenesis }\end{array}$ \\
\hline & & & & $\begin{array}{l}\text { 12.homophilic cell } \\
\text { adhesion via plasma } \\
\text { membrane adhesion } \\
\text { molecules }\end{array}$ & & $\begin{array}{l}\text { 12.dopaminergic } \\
\text { neuron differentiation }\end{array}$ & $\begin{array}{l}\text { 12.homophilic cell } \\
\text { adhesion via plasma } \\
\text { membrane adhesion } \\
\text { molecules }\end{array}$ \\
\hline & & & & $\begin{array}{l}\text { 13.sequence-specific } \\
\text { DNA binding }\end{array}$ & & $\begin{array}{l}\text { 13.integral } \\
\text { component of plasma } \\
\text { membrane }\end{array}$ & $\begin{array}{l}\text { 13.dopaminergic } \\
\text { neuron differentiation }\end{array}$ \\
\hline & & & & $\begin{array}{l}\text { 14.uterus } \\
\text { development }\end{array}$ & & $\begin{array}{l}\text { 14.DNA-binding } \\
\text { transcription factor } \\
\text { activity, RNA } \\
\text { polymerase II-specific }\end{array}$ & $\begin{array}{l}\text { 14.uterus } \\
\text { development }\end{array}$ \\
\hline & & & & $\begin{array}{l}\text { 15.negative regulation } \\
\text { of sprouting } \\
\text { angiogenesis } \\
\text { 16.calcium ion binding }\end{array}$ & & & $\begin{array}{l}\text { 15.negative regulation } \\
\text { of sprouting } \\
\text { angiogenesis } \\
\text { 16.chemical synaptic } \\
\text { transmission }\end{array}$ \\
\hline & & & & $\begin{array}{l}\text { 17.extracellular matrix } \\
\text { organization }\end{array}$ & & & 17.cell junction \\
\hline & & & & $\begin{array}{l}\text { 18.neuropeptide } \\
\text { signaling pathway } \\
\text { 19.cell junction }\end{array}$ & & & $\begin{array}{l}\text { 18.neuropeptide } \\
\text { signaling pathway } \\
\text { 19.extracellular matrix } \\
\text { organization } \\
\text { 20.pancreas } \\
\text { development } \\
\text { 21.calcium ion binding } \\
\text { 22.DNA-binding } \\
\text { transcription factor } \\
\text { activity } \\
\text { 23.growth factor } \\
\text { activity }\end{array}$ \\
\hline & $\begin{array}{c}p< \\
0.05 \\
\& \\
\Delta \beta>0.1\end{array}$ & & $\begin{array}{l}\text { 1.neutrophil } \\
\text { degranulation }\end{array}$ & $\begin{array}{l}\text { 1.neutrophil } \\
\text { degranulation }\end{array}$ & & & \\
\hline
\end{tabular}

particular site(s), which were not methylated in the initial, preseparation analysis of the buffy coat.

For subsequent analysis, we calculated the $p<0.05$ cutoff using Bonferroni correction (z-score 5.29) and labeled as discordant all probes that fell outside of this range as outliers when standardized. The total number of discordant probe trios was $28,989(0.24 \%)$ out of $n^{\star} 412,481(n=29)$ included in the model. These values were filtered out of the data from all three types of samples. All analyses were then repeated with the new "filtered" dataset (called without discordant probes) to determine whether the differentially methylated regions or probes were actually false positives. We found that, regardless of the filtering criteria used, the changes were minor in terms of DMP and DMR (Table 2 left, without discordant probes) and did not seem to affect the top scoring GSEA sites (Table 2 right). 

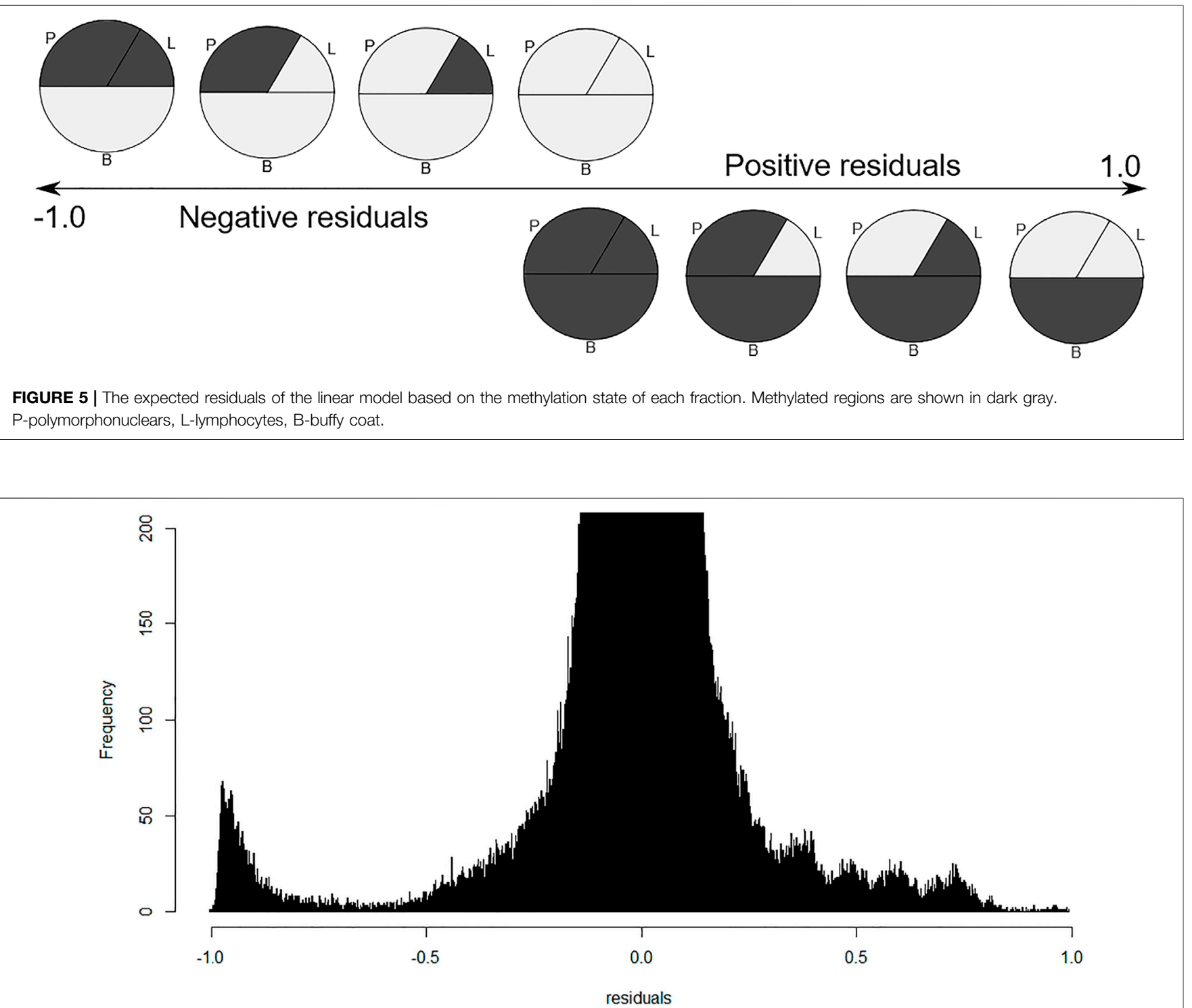

FIGURE 6 | Frequency of probes generated residuals after application of the fitted linear model; bin width is 0.001. Y-range is limited from 0-200 to allow visualization of important minority groups. Most of the probes centered around zero with a small peak in the furthest negative region indicative of a cluster of probes methylated in polymorphonuclears and lymphocytes but not in the original buffy coat.

\section{Analysis of Discordant Probes}

The number of discordant probes for which prediction of the methylation in the buffy coat was discordant from the prediction based on constituent fractions (PMN leukocytes and lymphocytes) was 23,438 (4.83\% of probes). The remaining 389,043 probes that passed filters were labeled as "concordant." We hypothesized that there would be something in the design or location of those probes that would predict discordance. We downloaded the Illumina $450 \mathrm{~K}$ manifest and analyzed the properties that differed between the two datasets.

After intersecting the locations of discordant probes with the unique Bismap ranges, only 11 of 23,438 discordant probes proved to map to non-unique segments in the bisulfiteconverted reference, which are expected to yield more reliable results. On the other hand, 212 of 389,043 concordant probes proved to be multi-mapped in the concordant probes. Both types of probes had identical uniqueness (99.95\%) rounded to four significant digits, suggesting that systematic mis-mapping does not explain discordance. Interestingly, 11,730 of 73,031 (16.06\%) probes that were filtered out by ChAMP default QC mapped to non-unique 50-mers according to this methodology. This high uniqueness of virtually all the probes that passed filters indicates that the probes are hybridizing with the expected sequences and that the discordance is an in-vitro, pre-measurement phenomenon. 


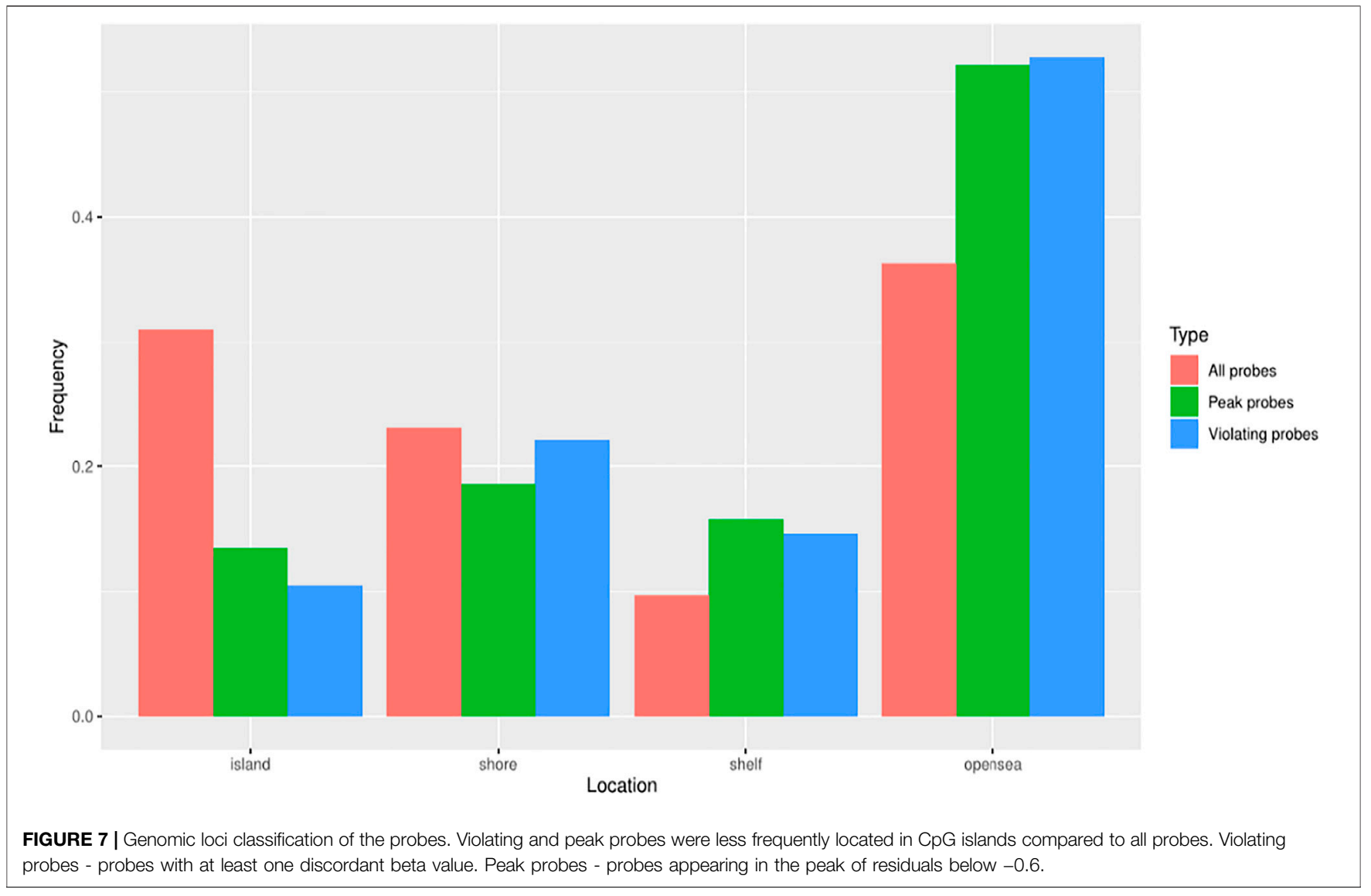

TABLE $4 \mid p$-values obtained by chi-squared proportion tests on different types of discordant probes with the pool of all probes, stratified by the CpG region. All results are significant at $\alpha=0.05$

\begin{tabular}{lcccc}
\hline $\begin{array}{l}\text { Comparison } \\
\text { with all probes }\end{array}$ & Islands & Shore & Shelf & Open sea \\
\hline $\begin{array}{l}\text { Violating probes } \\
\text { Peak probes }\end{array}$ & $<2.2 \mathrm{e}-16$ & $9.479 \mathrm{e}-08$ & $<2.2 \mathrm{e}-16$ & $<2.2 \mathrm{e}-16$ \\
& $<2.2 \mathrm{e}-16$ & $1.726 \mathrm{e}-15$ & $<2.2 \mathrm{e}-16$ & $<2.2 \mathrm{e}-16$
\end{tabular}

We also noted a prominent difference in guanine-cytosine (GC) content, and the discordant probes in the linear model had approximately $3 \%$ lower GC. One of the probes was discordant in 14 of 29 trio samples but had only a moderate GC content of $55 \%$. Similarly, many of the probes with a higher error rate had lower GC values.

As mappability and GC content strongly differ along the genome, and presumably correlate with the presence of $\mathrm{CpG}$ islands, we investigated the location of discordant probes and tried to determine any preference for genomic loci relative to $\mathrm{CpG}$ islands. To avoid effect of overrepresentation of individual probes without the understanding of the underlying process, we counted each probe only once regardless of the number of occurrences in the investigated groups. Resorting to the standard four groups-CpG islands, shores, shelves, and open sea-we plotted and tested the proportion of groups for all probes
$(412,481)$, discordant probes $(23,438)$, and the subset of probes giving the peak of residuals below -0.6 (peak probes, 4,535). We noted that the genomic location of both discordant groups (discordant and peak probes) was significantly different from the group of all probes (Figure 7; Table 4). These differences indicated that the discordant trios were most likely to be located in open sea regions, and least likely to be present in CpG islands.

\section{DISCUSSION}

Our present study reports several novel findings obtained through a comparative analysis of the methylation profile in buffy coat versus PMN and lymphocyte cell lines. First, the buffy coat methylation profile was representative of methylation patterns of derived cell lines. We characterized the genomewide methylation profile of the buffy coat, PMN and the lymphocytic fractions drawn from the same individual in 29 normotensive pregnancies across $>450,000 \mathrm{CpG}$ sites in genes across the entire genome. We performed pairwise comparisons that yielded a number of probes that are differentially methylated, but with relatively small differences in beta values. We found a very small percentage of differentially methylated CpG sites when the buffy coat was compared to the PMN fraction (2.96\%) and a greater percentage of differentially methylated $\mathrm{CpG}$ sites between PMN and lymphocytes (34.69\%), consistent with the fact that the 
PMN fraction is the main constituent of the buffy coat Second, differential methylation occurred in biological pathways that are specific for the derived cell lines, such as neutrophil degranulation and cytokine-mediated signaling pathways, consistent with the sensitivity of these cell-type specific pathways to perturbations during the cell separation process. Third, using a linear model we were able to identify approximately 29,000 probes for which the prediction of $\mathrm{CpG}$ methylation within the buffy coat is discordant from the prediction from constituent fractions. These discordant probes had a lower GC content, and the CpG sites involved also preferentially affected the open sea and shelf regions; discordant methylation seems to be an in vitro phenomenon and likely due to the separation process of the buffy coat.

To date, few studies have provided comparative analyses of different epigenetic profiles across different blood fractions in pregnancy. One notable example is a study of the cord blood, which showed that methylation in whole blood is reasonably comparable to buffy coat in a small number $(\underline{n}=8)$ of paired samples (Dou et al., 2018). However, the concordance between special cell populations (such as lymphocytes or monocytes) with either whole blood or buffy coat was not studied. To address cell type composition of complex tissues, we have previously developed and characterized in silico epigenomic deconvolution methods (Onuchic et al., 2016; Decamps et al., 2020) that infer DNA methylation of constituent cell types by minimizing residuals.

We now extend residual analysis to address the complexity of the blood samples with their multiple cell types by providing a novel approach to analyzing and interpreting methylation profiles from the tissue of origin (whole blood, buffy coat) and derived cell lines (PMN and lymphocyte cell lines). Negative residuals in the overall linear model indicate that at least one of the fractions changed its state from unmethylated to methylated in derived cell lines (i.e., PMN and lymphocytes), while the positive residuals representing the opposite process, were few. Most residuals in the interval between -0.7 and 0.7 seem balanced, in accordance with the expected normal distribution as a result of unobserved variation. On the other hand, close to $50 \%$ of discordant probes are grouped in a clear peak below -0.8 and have no substantial positive counterpart, i.e., the same probe being methylated in the buffy coat, but unmethylated in derived cell line(s), indicating strong preference towards methylation in PMN and lymphocytes. This targeted DNA inactivation, preferentially targeting isolated $\mathrm{CpGs}$ in the open-sea regions, could be the result of the separation process, and the mechanical/ chemical stress exerted on the cells removed from their normal medium.

While our study was performed on a relatively small sample size, a pairwise comparison of samples drawn from the same individual should limit the effects of potential confounders. We studied only normotensive pregnancies within $24 \mathrm{~h}$ prior to delivery, thus limiting the extrapolation of our results to other conditions with vastly different white blood cell composition or with selective methylation of a certain white blood cell fraction.

Our results have the potential to improve rigor and reproducibility of studies involving epigenomic profiling of buffy coat samples. For example, in the context of one of our previous studies, we identified a state of transient hypomethylation in normal early pregnancy compared with non-pregnancy (White et al., 2012). This hypomethylation would spontaneously revert after delivery. Our sample included patients close to delivery, suggesting a potential tendency towards global hypomethylation. DNA methylation can be affected by many factors including age (Bell et al., 2012), race, BMI, smoking, gestational diabetes (Wu et al., 2018), and preeclampsia (White et al., 2013). The patients in our study had healthy normotensive pregnancies, with a similar age range, a relatively homogeneous ethnicity, and free of major medical comorbidities that could affect DNA methylation. Some fetal DNA contamination was possible, but it likely represented a very small fraction (up to 6\% of total measured DNA) (Bischoff, 2002) and, therefore, it was unlikely to have significantly changed our results. However, in our original study, we could not firmly establish the relation between the DNA methylation profiles in buffy coat samples and that of constituent cell types. Our current results help establish this relation, thus improving both the rigor and biological interpretability of our results. Moreover, our results will help integrate results obtained from buffy coat samples and those obtained from profiling of isolated constituent cell types. Finally, our results are not limited to studies of pregnancy and have implications for numerous other studies involving DNA methylation profiling of buffy coat samples and constituent cell types.

A potential limitation of this study is that we did not account for the effect of DNA extraction techniques. DNA was isolated in samples using the AutoGenFlex DNA purification kit for the buffy coat and the neutrophil fraction, and manual extraction of DNA was performed for the lymphocytic fraction. The use of different methods for DNA isolation may affect methylation results, although the methylation mark is considered quite stable, but this is currently minimally discussed in the literature (Hjorthaug et al., 2018). Blood sample processing techniques, such as using Ficoll density centrifugation, can also potentially confound methylation. Finally, we used the Illumina $450 \mathrm{~K}$ array, which covers only $\sim 2 \%$ of total CpGs within the human genome. The Illumina Infinium Human Methylation 450, however, controls for the confounding and takes SNPs into account when analyzing output data. Future directions include using a different sample cohort and methodology to confirm our results. We hope to reproduce our findings in a larger, independent sample, and in a different study population that would confirm the stability of the methylome in the buffy coat and its sub-fractions.

Despite these limitations, our results demonstrate that the buffy coat methylation profile is representative of the methylation patterns in white blood cell types in normal pregnancy obtained using Illumina Human Methylation 450 BeadChip. Small differences in the buffy coat composition may confound the methylation analysis at a very small number of CpG sites, but this is not likely to affect most results. Current methods to adjust for cellular heterogeneity, either by excluding these differentially methylated genes, or, better yet, adjusting methylation data to account for these differences in buffy coat composition, improve the robustness of methylome analysis in buffy coat. Overall, our 
results support DNA methylation profiling of buffy coats as an acceptable approach for epigenomic profiling in pregnancy research and suggest that separation is likely only needed when studying lineage-specific diseases.

\section{DATA AVAILABILITY STATEMENT}

The datasets presented in this study can be found in an online repository. The name of the repository and accession link can be found below: OSF, https://osf.io/324ak/?view_only= 5c1c7cf5b77a40d3bb29b7d9c418f763.

\section{ETHICS STATEMENT}

The studies involving human participants were reviewed and approved by Mayo Clinic Institutional Review Board. The

\section{REFERENCES}

Adalsteinsson, B. T., Gudnason, H., Aspelund, T., Harris, T. B., Launer, L. J., Eiriksdottir, G., et al. (2012). Heterogeneity in white Blood Cells Has Potential to Confound DNA Methylation Measurements. PLoS One 7 (10), e46705. doi:10.1371/journal.pone.0046705

Bell, J. T., Tsai, P.-C., Yang, T.-P., Pidsley, R., Nisbet, J., Glass, D., et al. (2012). Epigenome-wide Scans Identify Differentially Methylated Regions for Age and Age-Related Phenotypes in a Healthy Ageing Population. Plos Genet. 8 (4), e1002629. doi:10.1371/journal.pgen.1002629

Bischoff, F. Z. (2002). Cell-free Fetal DNA and Intact Fetal Cells in Maternal Blood Circulation: Implications for First and Second Trimester Noninvasive Prenatal Diagnosis. Hum. Reprod. Update 8 (6), 493-500. doi:10.1093/humupd/8.6.493

Decamps, C., Privé, F., Privé, F., Bacher, R., Jost, D., Waguet, A., et al. (2020). Guidelines for Cell-type Heterogeneity Quantification Based on a Comparative Analysis of Reference-free DNA Methylation Deconvolution Software. BMC Bioinformatics 21 (1), 16. doi:10.1186/s12859-019-3307-2

Doi, A., Park, I.-H., Wen, B., Murakami, P., Aryee, M. J., Irizarry, R., et al. (2009). Differential Methylation of Tissue- and Cancer-specific CpG Island Shores Distinguishes Human Induced Pluripotent Stem Cells, Embryonic Stem Cells and Fibroblasts. Nat. Genet. 41 (12), 1350-1353. doi:10.1038/ng.471

Dou, J., Schmidt, R. J., Benke, K. S., Newschaffer, C., Hertz-Picciotto, I., Croen, L. A., et al. (2018). Cord Blood Buffy Coat DNA Methylation Is Comparable to Whole Cord Blood Methylation. Epigenetics 13 (1), 108-116. doi:10.1080/ 15592294.2017.1417710

Geeleher, P., Hartnett, L., Egan, L. J., Golden, A., Raja Ali, R. A., and Seoighe, C. (2013). Gene set Analysis Is Severely Biased when Applied to Genome-wide Methylation Data. Bioinformatics 29 (15), 1851-1857. doi:10.1093/ bioinformatics/btt311

Hellman, A., and Chess, A. (2007). Gene Body-specific Methylation on the Active X Chromosome. Science 315 (5815), 1141-1143. doi:10.1126/science.1136352

Hjorthaug, H. S., Gervin, K., Mowinckel, P., and Munthe-Kaas, M. C. (2018) Exploring the Influence from Whole Blood DNA Extraction Methods on Infinium 450K DNA Methylation. PLoS One 13 (12), e0208699. doi:10.1371/journal.pone.0208699

Hodges, E., Molaro, A., Dos Santos, C. O., Thekkat, P., Song, Q., Uren, P. J., et al. (2011). Directional DNA Methylation Changes and Complex Intermediate States Accompany Lineage Specificity in the Adult Hematopoietic Compartment. Mol. Cell 44 (1), 17-28. doi:10.1016/j.molcel.2011.08.026

Houseman, E. A., Kim, S., Kelsey, K. T., and Wiencke, J. K. (2015). DNA Methylation in Whole Blood: Uses and Challenges. Curr. Envir Health Rpt 2 (2), 145-154. doi:10.1007/s40572-015-0050-3 patients/participants provided their written informed consent to participate in this study.

\section{AUTHOR CONTRIBUTIONS}

Conception and design of the work: RG, IV, OM, WW, LT, JC, AM, NM, VG; Acquisition, analysis or interpretation of data for the work: RG, IV, OM, WW, LT, JC, AM, NM, VG; Drafting the article: RG, IV, OM, WW, LT, CJ, AM, NM, VG; Revising article critically for important intellectual content: RG, IV, OM, WW, LT, JC, AM, NM, VG.

\section{FUNDING}

This work was supported by the National Institutes of Health R01-HL136348.

Järemo, P., Lindahl, T. L., Lennmarken, C., and Forsgren, H. (2000). The Use of Platelet Density and Volume Measurements to Estimate the Severity of Preeclampsia. Eur. J. Clin. Invest. 30 (12), 1113-1118. doi:10.1046/j.13652362.2000.00753.x

Jones, P. A. (2012). Functions of DNA Methylation: Islands, Start Sites, Gene Bodies and beyond. Nat. Rev. Genet. 13 (7), 484-492. doi:10.1038/nrg3230

Karimzadeh, M., Ernst, C., Kundaje, A., and Hoffman, M. M. (2018). Umap and Bismap: Quantifying Genome and Methylome Mappability. Nucleic Acids Res. 46 (20), e120. doi:10.1093/nar/gky677

Klutstein, M., Nejman, D., Greenfield, R., and Cedar, H. (2016). DNA Methylation in Cancer and Aging. Cancer Res. 76 (12), 3446-3450. doi:10.1158/00085472.can-15-3278

Kuss-Duerkop, S. K., Westrich, J. A., and Pyeon, D. (2018). DNA Tumor Virus Regulation of Host DNA Methylation and its Implications for Immune Evasion and Oncogenesis. Viruses 10 (2), 82. doi:10.3390/v10020082

Luppi, P., Haluszczak, C., Betters, D., Richard, C. A., Trucco, M., and DeLoia, J. A. (2002). Monocytes Are Progressively Activated in the Circulation of Pregnant Women. J. Leukoc. Biol. 72 (5), 874-884. doi:10.1189/jlb.72.5.874

Luppi, P., Haluszczak, C., Trucco, M., and Deloia, J. A. (2002). Normal Pregnancy Is Associated with Peripheral Leukocyte Activation. Am. J. Reprod. Immunol. 47 (2), 72-81. doi:10.1034/j.1600-0897.2002.1o041.x

Naccasha, N., Gervasi, M.-T., Chaiworapongsa, T., Berman, S., Yoon, B. H., Maymon, E., et al. (2001). Phenotypic and Metabolic Characteristics of Monocytes and Granulocytes in normal Pregnancy and Maternal Infection. Am. J. Obstet. Gynecol. 185 (5), 1118-1123. doi:10.1067/mob.2001.117682

Onuchic, V., Hartmaier, R. J., Boone, D. N., Samuels, M. L., Patel, R. Y., White, W. M., et al. (2016). Epigenomic Deconvolution of Breast Tumors Reveals Metabolic Coupling between Constituent Cell Types. Cell Rep. 17 (8), 2075-2086. doi:10.1016/j.celrep.2016.10.057

Peters, T. J., Buckley, M. J., Statham, A. L., Pidsley, R., Samaras, K., V Lord, R., et al. (2015). De Novo identification of Differentially Methylated Regions in the Human Genome. Epigenetics \& Chromatin 8, 6. doi:10.1186/17568935-8-6

Phipson, B., Maksimovic, J., and Oshlack, A. (2016). missMethyl: an R Package for Analyzing Data from Illumina's HumanMethylation450 Platform. Bioinformatics 32 (2), 286-288. doi:10.1093/bioinformatics/btv560

Portela, A., and Esteller, M. (2010). Epigenetic Modifications and Human Disease. Nat. Biotechnol. 28 (10), 1057-1068. doi:10.1038/nbt.1685

Sacks, G., Sargent, I., and Redman, C. (1999). An Innate View of Human Pregnancy. Immunol. Today 20 (3), 114-118. doi:10.1016/s0167-5699(98) 01393-0

Smyth, G. K. (2004). Linear Models and Empirical Bayes Methods for Assessing Differential Expression in Microarray Experiments. Stat. Appl. Genet. Mol. Biol. 3, 1-25. doi:10.2202/1544-6115.1027 
Straussman, R., Nejman, D., Roberts, D., Steinfeld, I., Blum, B., Benvenisty, N., et al. (2009). Developmental Programming of CpG Island Methylation Profiles in the Human Genome. Nat. Struct. Mol. Biol. 16 (5), 564-571. doi:10.1038/ nsmb.1594

White, W. M., Brost, B. C., Sun, Z., Rose, C., Craici, I., Wagner, S. J., et al. (2012). Normal Early Pregnancy: a Transient State of Epigenetic Change Favoring Hypomethylation. Epigenetics 7 (7), 729-734. doi:10.4161/epi.20388

White, W. M., Brost, B., Sun, Z., Rose, C., Craici, I., Wagner, S. J., et al. (2013). Genome-wide Methylation Profiling Demonstrates Hypermethylation in Maternal Leukocyte DNA in Preeclamptic Compared to Normotensive Pregnancies. Hypertens. Pregnancy 32 (3), 257-269. doi:10.3109/ 10641955.2013.796970

White, W. M., Sun, Z., Borowski, K. S., Brost, B. C., Davies, N. P., Rose, C. H., et al. (2016). Preeclampsia/Eclampsia Candidate Genes Show Altered Methylation in Maternal Leukocytes of Preeclamptic Women at the Time of Delivery. Hypertens. Pregnancy 35 (3), 394-404. doi:10.3109/ 10641955.2016.1162315

Wu, P., Farrell, W. E., Haworth, K. E., Emes, R. D., Kitchen, M. O., Glossop, J. R., et al. (2018). Maternal Genome-wide DNA Methylation Profiling in Gestational Diabetes Shows Distinctive Disease-Associated Changes Relative to Matched Healthy Pregnancies. Epigenetics 13 (2), 122-128. doi:10.1080/ 15592294.2016.1166321
Young, M. D., Wakefield, M. J., Smyth, G. K., and Oshlack, A. (2010). Gene Ontology Analysis for RNA-Seq: Accounting for Selection Bias. Genome Biol. 11 (2), R14. doi:10.1186/gb-2010-11-2-r14

Conflict of Interest: The authors declare that the research was conducted in the absence of any commercial or financial relationships that could be construed as a potential conflict of interest.

Publisher's Note: All claims expressed in this article are solely those of the authors and do not necessarily represent those of their affiliated organizations, or those of the publisher, the editors, and the reviewers. Any product that may be evaluated in this article, or claim that may be made by its manufacturer, is not guaranteed or endorsed by the publisher.

Copyright (c) 2022 Ghamrawi, Velickovic, Milicevic, White, Thistlethwaite, Cunningham, Milosavljevic, Milic and Garovic. This is an open-access article distributed under the terms of the Creative Commons Attribution License (CC $B Y)$. The use, distribution or reproduction in other forums is permitted, provided the original author(s) and the copyright owner(s) are credited and that the original publication in this journal is cited, in accordance with accepted academic practice. No use, distribution or reproduction is permitted which does not comply with these terms. 